\title{
Mixed cavernous hemangioma-lymphangioma of the jejunum: detection by wireless capsule endoscopy
}

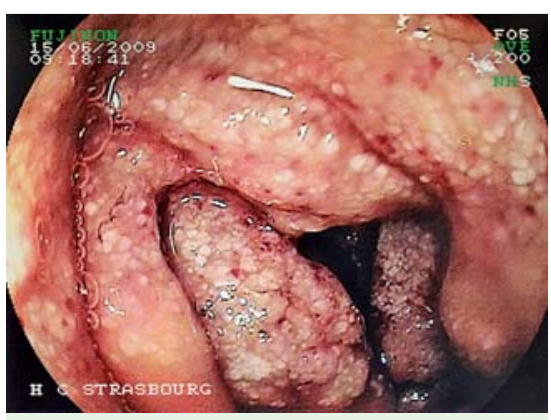

Fig. 1 Case 1. Double-balloon endoscopy showing a large hemi-circumferential lesion, with whitish carpet-like villi and red spots.

A 26-year-old woman (case 1) was referred for evaluation of recurrent episodes of melena. Gastroscopy, colonoscopy with ileoscopy, and small-bowel computed tomography (CT) scan were normal. Capsule endoscopy (Pill cam SB 2, Given Imaging, Yoqneam, Israel) disclosed a lesion with whitish carpet-like villi and superficial red spots with spontaneous bleeding at the proximal jejunum. At double-balloon enteroscopy (Fujinon, Saitama, Japan) the lesion occupied two-thirds of the lumen (๑ Fig. 1).

The involved segment was resected by laparoscopy ( $\bullet$ Fig. 2).

Microscopy showed a mixed lesion with a central core of dilated cavernous vascular channels surrounded by dilated lymph vessels ( $\bullet$ Fig. 3 ).

The diagnosis of a mixed cavernous hemangioma-lymphangioma was confirmed by immunostaining [1] ( $\bullet$ Fig. 4).

A 59-year-old man (case 2) was admitted for two episodes of melena. Gastroscopy and colonoscopy were normal. Capsule enteroscopy revealed a polypoid lesion covered by whitish and red spots at the proximal jejunum ( Fig.5), which was confirmed on double-balloon enteroscopy.

The patient underwent single-port laparoscopy and the involved segment was resected. The lesion, $3.5 \mathrm{~cm} \times 7 \mathrm{~cm}$ in size, corresponded to a mixed cavernous hemangioma-lymphangioma.

Gastrointestinal cavernous hemangiomas are congenital benign vascular lesions that are usually located in the jejunum. Their endoscopic appearance at enteros-
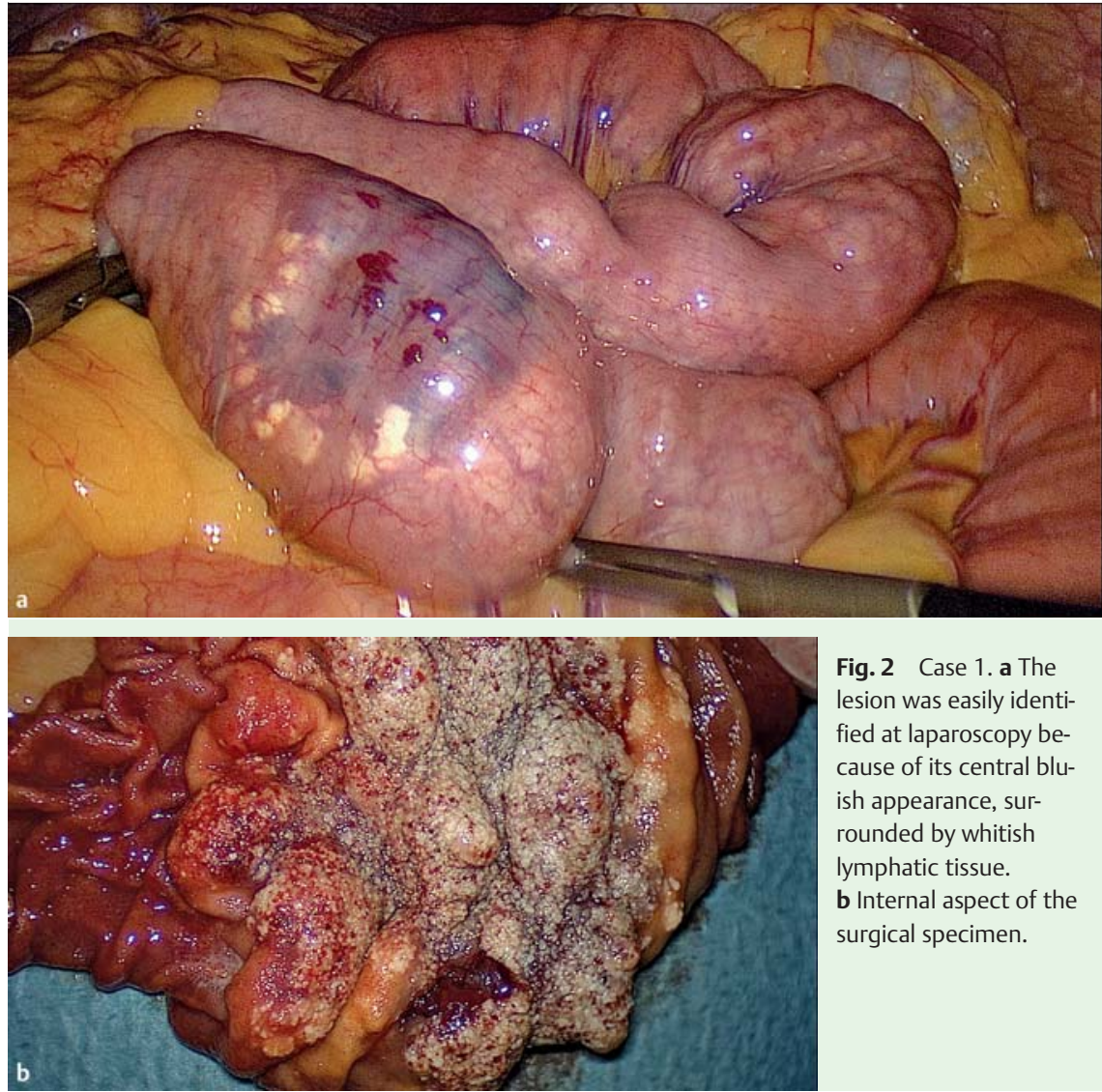

Fig. 2 Case 1. a The lesion was easily identified at laparoscopy because of its central bluish appearance, surrounded by whitish lymphatic tissue. b Internal aspect of the surgical specimen.

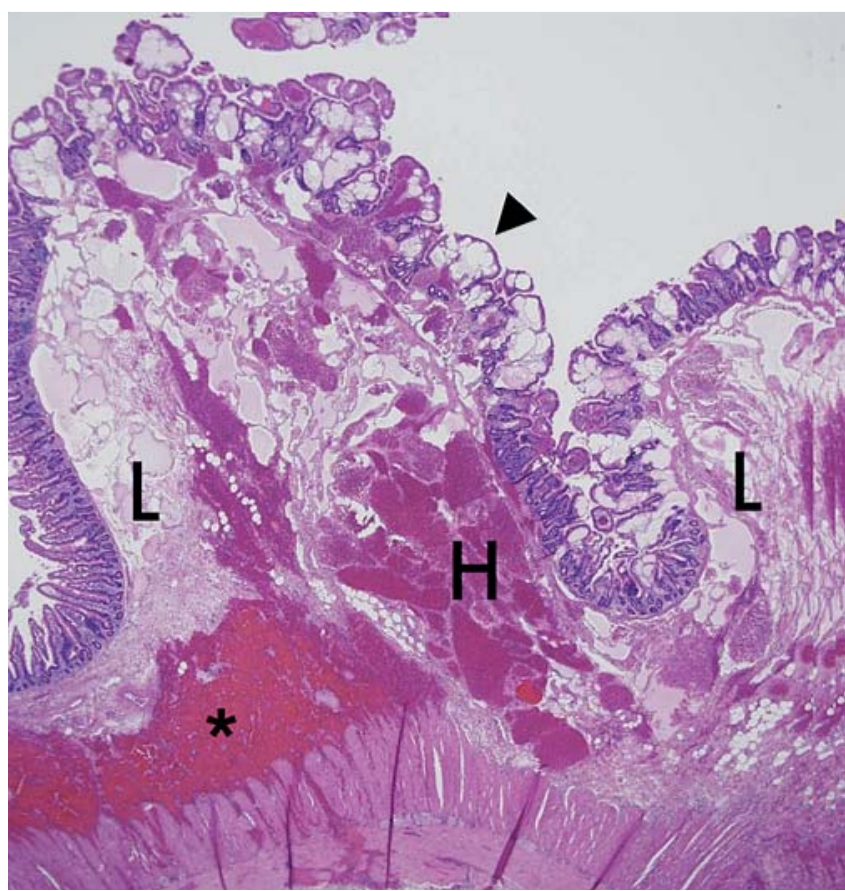

Fig. 3 Case 1. The lesion involving the mucosa and the submucosa is a cavernous hemangioma $(\mathrm{H})$ surrounded by dilated cavernous lymphatic channels (L). The overlying intact mucosa is thickened by numerous lymphangiectasis (arrowhead). The asterisk indicates a focal hemorrhage in contact with the muscularis propria (hematoxylin and eosin staining; original magnification $\times 20$ ). 

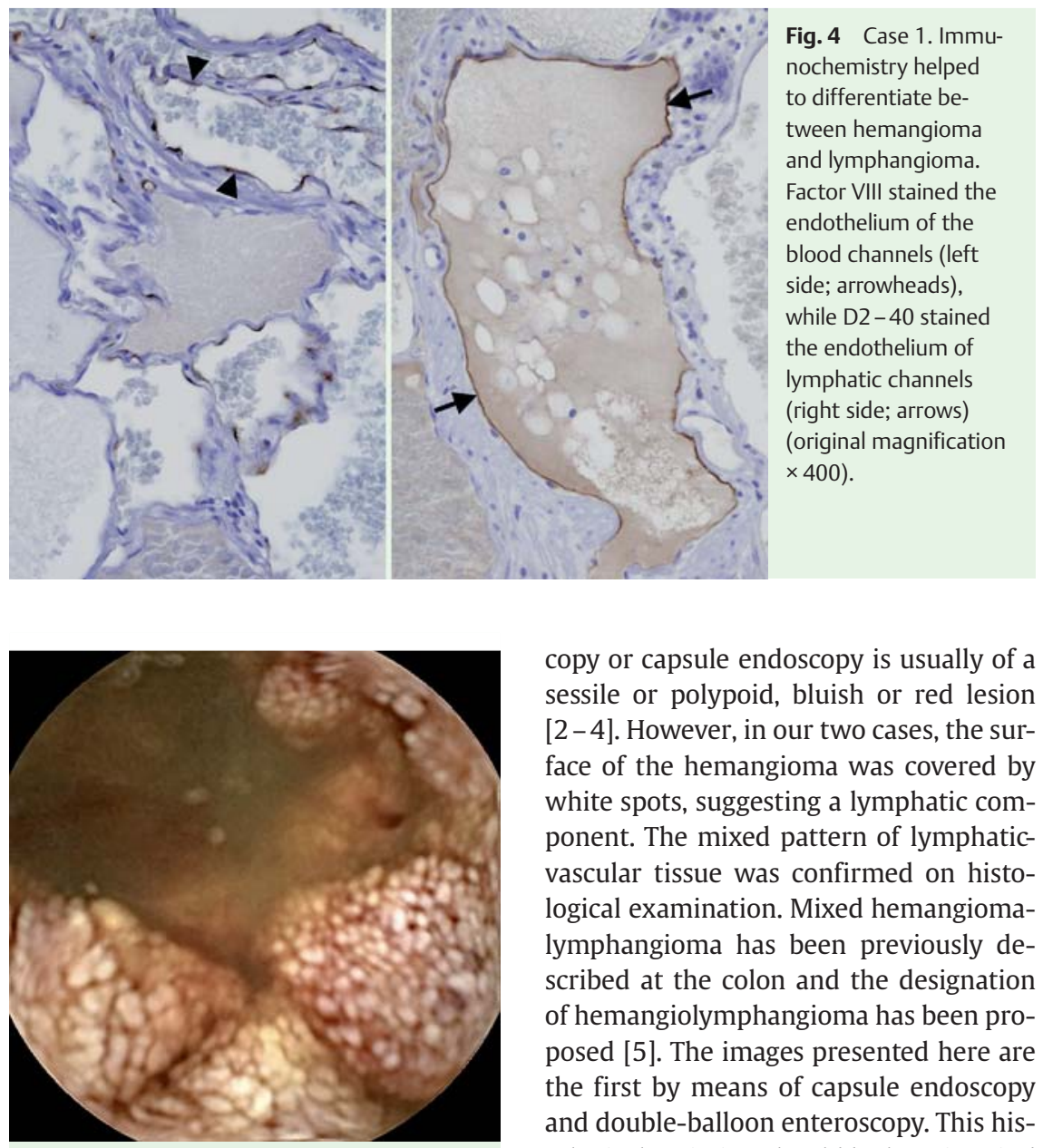

Fig. 5 Case 2. Capsule enteroscopy: vascular lesion with whitish spots resembling lymphangiectasis. copy or capsule endoscopy is usually of a sessile or polypoid, bluish or red lesion [2-4]. However, in our two cases, the surface of the hemangioma was covered by white spots, suggesting a lymphatic component. The mixed pattern of lymphaticvascular tissue was confirmed on histological examination. Mixed hemangiomalymphangioma has been previously described at the colon and the designation of hemangiolymphangioma has been proposed [5]. The images presented here are the first by means of capsule endoscopy and double-balloon enteroscopy. This histological variation should be kept in mind in the differential diagnosis of vascular lesions with lymphangiectasias.

Endoscopy_UCTN_Code_CCL_1AC_2AB

Competing interests: None
G. Mavrogenis ${ }^{1}$, D. Coumaros ${ }^{1}$, N. Lakhrib $^{1}$, C. Renard ${ }^{2}$, J. P. Bellocq ${ }^{2}$, J. Leroy ${ }^{3}$

1 Department of Gastroenterology, University Hospital, Strasbourg, France

2 Department of Histopathology, University Hospital, Strasbourg, France

3 Department of Digestive Surgery, University Hospital, Strasbourg, France

\section{References}

1 Kahn HJ, Bailey D, Marks A. Monoclonal antibody D2-40, a new marker of lymphatic endothelium, reacts with Kaposi's sarcoma and a subset of angiosarcomas. Mod Pathol 2002; 15: 434-440

2 Chen $\mathrm{CH}$, Jones J. Profound iron deficiency anemia caused by a small-intestinal cavernous hemangioma. Gastrointest Endosc 2009; 69: $1392-1393$

3 Quentin V, Lermite E, Lebigot J et al. Small bowel cavernous hemangioma: wireless capsule diagnosis of a surgical case. Gastrointest Endosc 2007; 65: 551 - 552

4 Willert RP, Chong AK. Multiple cavernous hemangiomas with iron deficiency anemia successfully treated with double-balloon enteroscopy. Gastrointest Endosc 2008; 67: $765-766$

5 Sylla P, Deutsch G, Luo J et al. Cavernous, arteriovenous, and mixed hemangioma-lymphangioma of the rectosigmoid: rare causes of rectal bleeding-case series and review of the literature. Int J Colorectal Dis 2008; 23: $653-658$

\section{Bibliography}

DOI $10.1055 / \mathrm{s}-0030-1256400$

Endoscopy 2011; 43: E217 -E218

(c) Georg Thieme Verlag KG Stuttgart · New York . ISSN 0013-726X

\section{Corresponding author \\ D. Coumaros \\ IRCAD/EITS \\ University Hospital \\ 1 Place de l'Hôpital \\ 67091 Strasbourg \\ France \\ Fax: +333-887-51521}

coumarosd@wanadoo.fr 